\title{
DO FORMALISMO DIDÁTICO À EXPERIÊNCIA DA CONSCIÊNCIA: PAULO FREIRE E A SUBSTANTIVIDADE DEMOCRÁTICA NA ESCOLA PÚBLICA-POPULAR
}

\author{
DEL FORMALISMO DIDÁCTICO HACIA LA EXPERIENCIA DE LA CONCIENCIA: \\ PAULO FREIRE Y LA SUBSTANTIVIDAD DEMOCRATICA EN LA ESCUELA \\ PÚBLICA-POPULAR
}

\begin{abstract}
FROM DIDACTIC FORMALISM TO THE EXPERIENCE OF CONSCIOUSNESS: PAULO FREIRE AND THE DEMOCRATIC SUBSTANTIVITY IN THE PUBLICPOPULAR SCHOOL
\end{abstract}

\author{
Gomercindo GHIGGI ${ }^{1}$ \\ Priscila Monteiro CHAVES ${ }^{2}$ \\ Dirlei de Azambuja PEREIRA ${ }^{3}$
}

RESUMO: O presente estudo de cunho teórico-bibliográfico ancora-se na teoria freiriana para denunciar a obsolescência do papel da didática no que compete à experiência da consciência (HEGEL, 2014), bem como visa analisar a sua equivocada tentativa de dar proeminência à socialização dos aspectos culturais já convencionados. A constituição de um fluxo de divulgadores, admiradores e comentadores concentrados em universidades e que, sob a égide da salvaguarda da tradição intelectual e do discurso revolucionário de Freire, acabou por convertê-lo em um autor (BRAYNER, 2015). Além de atenuar uma concepção pedagógica de educação popular, preceitos estéticos, culturais e políticos que fundamentam para além do fazer da sala de aula foram se modificando. Assumir a diretividade da educação em uma perspectiva democrática é um dos pontos de reflexão deste estudo. Uma educação para a liberdade nada tem a ver com o espontaneísmo. Todavia, a didática tem sido uma área bastante prejudicada por uma leitura descompromissada dos mais recentes paradigmas filosóficos educacionais. Posicionamentos equivocados vêm sendo adotados em nome de um suposto respeito à individualidade do aluno, que nada mais são que um espontaneísmo licencioso sob o pretexto de práticas não diretivas. Esse conflito demanda melhor elucidação da relação intrínseca entre os aspectos políticos didático-pedagógicos e a liberdade da experiência da consciência, a qual Freire (1990) chamou de substantividade democrática.

\footnotetext{
${ }^{1}$ Universidade Federal de Pelotas (UFPel), Pelotas - RS - Brasil. Professor Titular Aposentado da Faculdade de Educação (FaE) e do Programa de Pós-Graduação em Educação (PPGE) da UFPel. Pesquisador do Grupo de Pesquisa Filosofia, Educação e Práxis Social (FEPráxiS) - UFPel. ORCID <https://orcid.org/0000-0001-97222424>. E-mail: gghiggi@terra.com.br

${ }^{2}$ Universidade do Oeste de Santa Catarina (UNOESC), Campus Joaçaba, Joaçaba - SC - Brasil. Professora Permanente do Programa de Pós-Graduação em Educação da Universidade do Oeste de Santa Catarina. Líder do Grupo de Pesquisa Educação, Políticas Públicas e Cidadania da Unoesc e pesquisadora do Grupo de Pesquisa Filosofia, Educação e Práxis Social (FEPráxiS) da UFPel. ORCID <http://orcid.org/0000-0002-3986-6157>. Email: priscila.chaves@unoesc.edu.br

${ }^{3}$ Universidade Federal de Pelotas (UFPel), Pelotas - RS - Brasil. Professor Adjunto da Faculdade de Educação da Universidade Federal de Pelotas. Vice-líder do Grupo de Pesquisa Filosofia, Educação e Práxis Social (FEPráxiS) da UFPel. ORCID <https://orcid.org/0000-0002-6487-4028>. E-mail: pereiradirlei@gmail.com
} 
PALAVRAS-CHAVE: Substantividade democrática. Experiência da consciência. Paulo Freire. Didática. Escola pública-popular.

RESUMEN: El presente estudio de cuño teórico-bibliográfico se apoya en la teoría freiriana para denunciar la obsolescencia del papel de la didáctica en lo que se refiere a la experiencia de la conciencia (HEGEL, 2014), bien como visa a analizar a su equivocado intento de dar preeminencia a la socialización de los aspectos culturales ya convenidos. La constitución de un flujo de divulgadores, admiradores y comentadores concentrados en las universidades e que, bajo la égida de la salvaguardia de la tradición intelectual y del discurso revolucionario de Freire, acabó por convertirlo en un autor (BRAYNER, 2015). Además de atenuar una concepción pedagógica de educación popular, preceptos estéticos, culturales y políticos que fundamentan para más allá del quehacer en el salón de clases, que fueron cambiados. Asumir la directividad de la educación en una perspectiva democrática es uno de los puntos de reflexión de este estudio. Una educación para la libertad nada tiene que ver con el espontaneísmo. Todavía, la didáctica ha sido un área muy perjudicada por una lectura descomprometida de los más recientes paradigmas filosóficos educacionales. Posicionamientos equivocados están siendo adoptados en nombre de un posible respeto a la individualidad del alumno, que son nada más que espontaneísmo licencioso bajo el pretexto de prácticas no directivas. Ese conflicto demanda mejor elucidación de la relación intrínseca de entre los aspectos políticos, didácticos-pedagógicos y la libertad de la experiencia de la conciencia a que Freire (1990) ha llamado sustantividad democrática.

PALABRAS-CLAVE: Sustantividad democrática. Experiencia de la conciencia. Paulo Freire. Didáctica. Escuela pública-popular.

ABSTRACT: This theoretical-bibliographic study is based on Paulo Freire's theory to denounce the neglect of the didactic function in the development of the experience of consciousness (HEGEL, 2014) as well as its objective is to analyze its misguided attempt to give prominence to the socialization of the cultural aspects already agreements. The formation of a flow of disseminators, admirers and commentators concentrated in universities and who, under the protection of Freire's intellectual tradition and revolutionary discourse, eventually turned him into an author (BRAYNER, 2015). In addition to weakening a pedagogical conception of popular education, aesthetic, cultural and political foundations that underlie beyond the classroom, have been modified. Assuming the directivity of education in a democratic perspective is one of the points of reflection of this study. An education for freedom has nothing to do with spontaneism. However, didactics has been an area greatly impaired by a reading that is not committed to the latest philosophical educational paradigms. Misplaced positions have been adopted in the name of a supposed respect for the individuality of the student, who are nothing more than a licentious spontaneism under the pretext of non-directive practices. This conflict shows the need for a better explanation of the intrinsic relationship between didactic-pedagogical political aspects and the freedom of the experience of consciousness, which Freire (1990) called democratic substantivity.

KEYWORDS: Democratic substantivity. Experience of consciousness. Paulo Freire. Didactics. Public-popular school. 


\section{Introdução}

No campo da prática docente nada é mais importante que observar e observar novamente, pensar sobre a ação e pensar também sobre o pensamento. Essas afirmações incomodam aqueles que ainda difundem no contexto educacional metodologias, objetivos e avaliações como prescrições bem-sucedidas e de fácil aplicabilidade aqui e ali (FREIRE, 1990). Parafraseando Jorge Luis Borges, é possível dizer que o conceito de aula definitiva não corresponde senão à religião ou ao cansaço (2008). A complexidade está na aula, pois ali está o encontro, o processo dialógico e a prática dos homens. Nada sobre a cultura ou sobre a especificidade humana é passível de ser reduzido a uma simplificação, pois toda tentativa de tal movimento está fadada ou ao apagamento de aspectos relevantes ou à camuflagem de questões profundamente idiossincráticas de cada um.

Entretanto, essa simplificação vem tomando espaço na prática docente e o saber como vem sendo a razão de ser da formação pedagógica, ganhando primazia em detrimento de um saber que, ou pensar com. Vera Maria Candau (2012) apontou esse saber como, quando desprovido de fundamentação e posicionamento crítico, de formalismo didático, o qual é necessário que seja superado junto com a busca pelo método único capaz de ensinar tudo a todos. Uma fundamental condição para a construção dessa compreensão é dar prioridade às propriedades essenciais da realidade da sala de aula, que advém de uma rigorosa pesquisa que não se contenta com meras listas de aspectos fenomênicos aparentes desse real, como questões de pouca complexidade social e cultural, que manifestem o supérfluo e esqueçam das condições de existência em que vivem as pessoas. Outra relevante condição é que essas propriedades, pela sua própria natureza enquanto essenciais do real pesquisado, cumpram o papel de incitar e fazer falar os processos internos desse real e, ao mesmo tempo, impliquem a curiosidade acerca do conhecimento científico ou organizado (OLIVEIRA, 1994).

Nesse sentido que o formalismo didático não tem mais lugar no planejamento da prática docente que queira garantir a experiência formativa, uma vez que, conforme defende José Carlos Libâneo (2012), cabe ao educador ser capaz de agregar os objetivos e as condições concretas de cada situação didática. Essas condições concretas, sobre as quais fala o autor, não são apenas os fatores sociais, econômicos, culturais, psicológicos, organizacionais e metodológicos (que os professores entendem como levar em conta a realidade do aluno e de sua prática social), referem-se, especialmente, às decisões didáticopedagógicas que toma o professor com base nesses fatores, na medida em que elas, trazidas para o âmbito do contexto escolar, intervêm e penetram os objetivos, conteúdos e métodos. 
Motivado por essas palavras introdutórias, o presente estudo, de cunho teóricobibliográfico, ancora-se na teoria freiriana para denunciar a obsolescência do papel da didática no que compete à experiência da consciência, bem como visa analisar a sua equivocada tentativa de dar proeminência à socialização dos aspectos culturais já convencionados.

Elege-se Freire para tal empreitada por ser, quiçá, um filósofo que dá coerência e substância às raízes críticas da pedagogia e, com isso, promove feitos coletivos que são capazes de sustentar a ideia de que a educação serve à transformação, pela formação de identidades e subjetividades, trazendo para o cenário social novas e esquecidas vitalidades ainda tão necessárias. Freire, considerando sua influência nas reflexões de McLaren, porque é capaz de ajudar teóricos críticos americanos, por exemplo, a reconhecer que a atividade pedagógica dominante, normalmente presente em escolas "democráticas, estava firmemente acorrentada a uma ordem social liberal-capitalista que reproduz a desigualdade a nível ideológico, [...] sob a bandeira da agência autônoma e da livre competição no mercado capitalista” (MCLAREN, 1999, p. 28). Freire, porque constrói e teoriza a prática, não reduzida à experiência imediata, e desconstrói axiomas filosófico-pedagógicos, combatendo absolutismos dogmático-autoritários e relativismos licenciosos, cujos preconceitos e dogmas são balizas permanentes à demarcação dos campos epistemológico e político.

É forçoso colacionar a validade da teoria freiriana com as urgências do contexto educacional postas pelo agora. Reconsiderar a proposta de Freire significa reconhecer que seu programa político-pedagógico é projeto possível que fortalece a construção contrahegemônica necessária para enfrentar fatalismos culturais excludentes, quando se impõem como único expediente. Se faz relevante ainda realizar estudos sobre processos educacionais em Freire partindo, segundo Torres (1998), da "dupla perspectiva: usando a lente da classe hegemônica - reprodução de relações sociais de produção - e usando a lente das classes subordinadas - educação como forma de construir uma nova hegemonia" (p. 97). Para o autor, a importância da educação está na reconstrução “da cultura do oprimido, particularmente através da noção de elaboração sistemática do conhecimento popular [...] como instrumento de luta da contra-hegemonia" (1998, p. 97). Torres conclui esse juízo afirmando que "a noção de Freire de uma relação dialética entre a liderança revolucionária e as massas tem um terreno rico nas práticas educacionais [...] para desenvolver a liderança de trabalhadores" (TORRES, 1998, p. 97).

Freire é o teórico-pedagogo central para o presente estudo porque, enquanto pensador do seu tempo, disponibiliza fundamentos para problematizar a escola em contexto, não por certezas absolutas, atestado de falência da capacidade humana nos humanos, nem índice de 
rigor teórico e conceitual, mas pela incitação de ideias que propõem referenciar práticas humanas, mantendo, como centralidade, a permanente possibilidade da dúvida como princípio epistemológico e político. Por isso é possível dizer que Freire coloca à disposição do mundo contemporâneo possibilidades de confrontos teórico-práticos referentes à totalidade das relações, o que torna fundamental a problematização de verdades absolutas também no campo da didática e da prática docente. Freire, porque busca refundamentar a educação em sua base epistemológica e ética, condição de possibilidade de exercício mínimo de si com vistas ao que é ontologicamente máximo na relação humana, que não está desvencilhado do trabalho pedagógico. É pensador e educador que põe em cena o sujeito da educação não em perspectiva metafísica pura, mas na condição histórica em que vive, tornando-se intersubjetivo de suas relações em comunhão ou confronto com outros sujeitos, sempre em condições de sensibilidade à reciprocidade; sujeito, não na perspectiva ocidental-cartesiana, mas ser histórico e social que vai constituindo-se, sem negar a dimensão metafísicoontológica que carrega. Freire porque seu "vocabulário filosófico permite ao mundo [...] adquirir visibilidade", não reduzindo o "o mundo a um texto. Em vez disso, estipula as condições de possibilidade de discursos diversos, concorrentes e conflituais" (MCLAREN, 1998, p. 66).

Recorre-se a Freire pois o campo da didática necessita de práticas pautadas pelas intervenções sociais autônomas e criativas, a partir do que a liberdade e a autonomia podem constituir, pois a obra de Freire permite declarar que há uma diretriz que possibilita fundamentar a epistemologia, a política e a pedagogia, o que torna a retomada de suas concepções necessária, enquanto eixo fundamental à reflexão em torno de projeto histórico. Freire porque ajuda a sustentar que o projeto de organização das relações que se dão na escola, pois relações humanas, ora em andamento, deve ser radicalmente questionado pelas suas práticas e seus conceitos, postos em um clima de constante tensão.

\section{A crítica ao formalismo didático e seus desdobramentos}

Libâneo (2012), um dos mais referenciados pesquisadores da didática no contexto brasileiro, afirma que a especificidade epistemológica dessa área reside no seu "processo instrucional [...] que orienta e assegura a unidade entre o aprender e o ensinar na relação com o saber, em situações contextualizadas" (p. 44). Segundo ele, nessas situações os alunos são guiados para a ampliação de "sua autonomia, no sentido de apropriar-se dos produtos da 
experiência humana na cultura e na ciência, visando o desenvolvimento humano" (LIBÂNEO, 2012, p. 44).

Para Candau, se a didática for adotada em uma concepção que enfoque seu caráter instrumental, então ela "é concebida como um conjunto de conhecimentos técnicos sobre o 'como fazer' pedagógico, conhecimentos estes apresentados de forma universal e, consequentemente, desvinculados dos problemas relativos ao sentido e aos fins da educação" (2013, p. 14). Refere-se então a um esvaziamento de seus fins, de seus "conteúdos específicos, assim como do contexto sociocultural concreto em que foram gerados" (2013, p. 14). Candau (2013) manifesta a intrínseca relação que há entre forma-conteúdo e como isso se reflete nos modos de compreensão do como ensinar. Nesse âmbito, há que se assinalar uma característica basilar: a tentativa constante de se constituir uma outra postura, na qual o diálogo e o conflito com diversas formas de olhar para a pedagogia são essenciais. De modo que essas outras posturas que vão sendo constituídas contrapõem aquilo que se tem por hábito apontar como pedagogia tradicional.

De forma um tanto atualizada e reforçando aspectos epistemológicos, Batalloso Navas pontuou que há, mais do que nunca, a necessidade de desconstrução de uma percepção da didática com o fim de decompô-la em elementos. Com isso, se quer dizer do quão forçoso se tornou percebê-la em sua complexidade, a ponto de compreender que, muito provavelmente, a mais diligente didática seja aquela que não se estabelece, a que não se institui, a que não está designada, uma vez que, de fato, se com algo ela contribui, será, mormente, por meio das conjunturas reflexivas do agora de uma ação viva pautada pela comunicação e por outros modos de relação dos homens (2010).

Em diversas vezes, ao constatar esse formalismo didático como modus operandi de grande parte dos profissionais de educação e perceber que não há mais como escapar do atendimento às necessidades latentes na escola, o método Paulo Freire ganha status de "Política Nacional de Educação Popular vinculada à Secretaria de Articulação Social da Presidência da República e que culmina com a elaboração e publicação de um Marco de Referência (2014) ${ }^{4 » ”}$ (BRAYER, 2015, p. 15). Segundo o autor, essa institucionalização da subversão é deveras conflitante, e o

[...] interesse do estado em se tornar "pedagogo", através de uma operação estratégica que transforma as relações políticas que estão na base dos

4 BRASIL. Secretária-Geral da Presidência da República. Secretaria Nacional de Articulação Social Departamento de Educação Popular e Mobilização Cidadã. Marco de Referência da Educação Popular para as Políticas Públicas. Brasília: 2014. 
agenciamentos públicos (e a formação dos atores sociais - em geral, "populares" - seja para elaborá-las, seja para monitorá-las) em relações pedagógicas: uma espécie de pedagogização das políticas públicas, políticas que são sempre o resultado de amplos e contínuos conflitos em torno de significados sociais, aplicando-se o "método" freireano para concebê-las e executá-las. Como se seguindo o modelo da problematização, conscientização, transformação na formação dos atores e na discussão das políticas, pudéssemos obter a legitimidade ideológica que um suposto "diálogo libertador" ofereceria, apoiando-se, além do mais, em conceitos como amorosidade curiosamente tomado como princípio... epistemológico! No entanto, o nó da questão não é o "método": é o princípio que o orienta (2015, p. 15, grifos nossos).

Se por um lado é necessário ponderar a importância dada ao chamado Método Paulo Freire no plano de uma de uma política pública, por outro, torna-se imperioso o cuidado quanto à pedagogização de tal proposta, quando sua leitura, compreensão e operacionalização se assemelham a um receituário, portanto, sendo incapaz de potencializar práxis políticopedagógicas, de matriz freiriana, com vistas à transformação social radical. Quanto ao termo método, o próprio Freire resistia à utilização do mesmo, dado o seu uso equivocado. Em entrevista ao jornal Pasquim (1978), Freire fez uma provocativa distinção, a saber:

Eu tenho até minhas dúvidas se se pode falar de método. E há, há um método. Aí é que está um dos equívocos dos que, por ideologia, analisam o que fiz procurando um método pedagógico, quando o que deveriam fazer é analisar procurando um método de conhecimento e, ao caracterizar o método de conhecimento, dizer "mas, esse método de conhecimento é a própria pedagogia." Entendes? O caminho era o caminho epistemológico. Evidentemente, tem gente que descobriu isso. [...] Esse é approach que eu acho correto. Então, não é o método no sentido se é ba-be-bi-bo-bu. Se o sujeito ler direitinho os textos que eu tenho escrito, sobretudo os recentes, sobre o problema da alfabetização, ele descobre que o que eu estou fazendo é teoria do conhecimento. A alfabetização enquanto um momento da teoria do conhecimento (FREIRE, 1978, p. 8).

Nessa mesma vereda, Moacir Gadotti, notável estudioso da obra de Freire, também advertia que "a rigor não se poderia falar em 'método' Paulo Freire pois se trata muito mais de uma teoria do conhecimento e de uma filosofia da educação do que de um método de ensino" (1989, p. 32). As diferenciações são oportunas, no que concerne à discussão aqui empreendida, pelo fato de que a empregabilidade do vocábulo método, quando associado à teoria de Paulo Freire e, consequentemente, utilizado como uma possível base para uma proposta didático-pedagógica, levaria à constituição de práticas educativas destoantes, em conteúdo e forma, ao que intenciona a filosofia freiriana. Resultado dessa má compreensão do que advoga o método Paulo Freire, emerge um conjunto de ações educativas distanciadas de 
uma construção protagonista dos envolvidos no processo pedagógico, incapazes de potencializar espaços de elaboração crítica e criativa, de respeitarem a substatividade democrática como condição sine qua non para a emergência de uma práxis verdadeiramente dialógica, coletiva e humanizadora, como será abordado nas próximas seções. O formalismo didático e pedagógico, resultante dos processos de padronização de preceitos e práticas democráticas em suas origens, fez suscitar propostas educacionais que normatizaram e engessaram a ação educativa, o que vem acarretando entraves à emergência de um ato pedagógico que auxilie os educandos a realizar a leitura da palavra e do mundo, pressupostos inerentes à teoria de Paulo Freire.

\section{A experiência da consciência e o movimento praxiológico}

Um dos principais impasses do formalismo didático refere-se a uma precária mediação daquilo que se quer conhecer, não originalmente, mas bastante abordada por um dos filósofos lidos por Freire - Friedrich Hegel - na obra Fenomenologia do Espírito. Hegel aponta a fragilidade de uma tentativa de formação que visa a fins imediatos, que "pretende ser mais que o início do conhecimento, e valer por conhecimento efetivo" (2014, p. 24). Para ele, nesse caso, essa tentativa "deve ser contada entre as invenções que servem para dar voltas ao redor da coisa mesma combinando a aparência de seriedade e de esforço com a carência efetiva de ambos" (2014, p. 24). Se o vir-a-ser compõe a sua efetividade, "a coisa mesma não se esgota em seu fim, mas em sua atualização" (2014, p. 24), que ocorre pelo longo percurso trilhado pela consciência.

Se a cultura antiga era carente da ideia de movimento, a conservação do que é negado - enquanto componente dos momentos anteriores - é um dos pressupostos da experiência da consciência, segundo Hegel, como busca do aprimoramento da força antecedente por meio do movimento. Ainda que as formas se diferenciem e se repilam pela manifestação de sua incompatibilidade, "o botão desaparece no desabrochar da flor, e poderia dizer-se que a flor o refuta; do mesmo modo que o fruto faz a flor parecer um falso ser-aí da planta, pondo-se como sua verdade em lugar da flor" (HEGEL, 2014, p. 33). O que o filósofo defende é que a passagem por esses momentos estão permeadas por um "tornar-se outro que deve ser retomado e é uma mediação" (2014, p. 33). Em tal processo, a "natureza fluida faz delas momentos da unidade orgânica, na qual, longe de se contradizerem, todos são igualmente necessários" (HEGEL, 2014, p. 24, grifos nossos). 
Ainda na mesma obra, Hegel aposta na organicidade do vir-a-ser, que nada tem de muito diverso da verdadeira forma, que se apresenta "como simples no resultado - ou melhor, que é justamente esse Ser retornado à simplicidade" (2014, p. 34) - e está atrelado ao movimento de reconciliação da própria consciência. "O objeto conhecido em geral, pelo fato mesmo de ser conhecido, não é reconhecido" (HEGEL, 2014, p. 19). Para Hegel, essa seria a forma mais comum de "iludir a si mesmo e de iludir os outros, consiste em supor no conhecer algo como já conhecido e deixá-lo como tal. Semelhante saber, como todo o ir e vir do discurso, e sem perceber como isto lhe aconteça, não sai do lugar” (2014, p. 19). A coisa não se afeiçoa "no seu fim mas em sua atuação, e o todo efetivo não é o resultado, a não ser juntamente com o seu devir. O fim para si é o universal sem vida, assim como a tendência é o puro impulso" (HEGEL, 2014, p. 6), em que permanece a carência de sua efetiva realidade.

Para tornar-se propriamente saber ou para produzir o elemento da ciência que é seu elemento puro o saber deve saber percorrer trabalhosamente um longo caminho. Esse devir, tal qual se mostrará no seu conteúdo e nas figuras que nele se apresentam não será o que neles se representa primeiramente como sendo introdução da ciência não cientifica a ciência. Será outrossim algo diferente da fundamentação da ciência. Acima de tudo será diferente do entusiasmo que começa com o saber absoluto já imediatamente, como que se desferindo um tiro de pistola, e se considera desobrigado com respeito a outros pontos de vista, declarando nada querer saber acerca deles (HEGEL, 2014, p. 17).

Quanto a esse longo caminho, Theodor W. Adorno sugere que "a substância do indivíduo [...] teve a paciência de percorrer essas formas na longa extensão do tempo e de empreender o gigantesco trabalho da história mundial" (1996, p. 39) e a esse trajeto se deve a experiência da consciência de si mesmo. A compreensão do que é o saber consiste no objetivo final da formação cultural, segundo Hegel. Ainda que ancorado na ideia de universalidade ${ }^{5}-$ isto é, a busca por uma síntese de um sujeito universal - a consciência de si, a que se refere, é pressuposto para uma apropriação subjetiva da cultura. "A ciência apresenta esse movimento de formação cultural em sua atualização e necessidade, como também apresenta em sua configuração o que já desceu ao nível de momento e propriedade do espírito” (2014, p. 39). Talvez por intermédio da teoria marxiana, mas é de Hegel que Freire toma de empréstimo a crítica à carência de movimento dos pensamentos determinados, muito útil para a constituição do que Freire chamou de sociedade instrumentalizada, alienada ou formalmente vazia, na qual

\footnotetext{
${ }^{5}$ A universalidade em Hegel não deve ser compreendida como uma norma ou ação imposta, todavia, ainda que pautada por um ideal a ser alcançado, historicamente constituída.
} 
aquilo que é comunicado tem o valor de próprio conhecimento, de modo avulso, isolado. Tal formalidade é dissimulada em nome do progresso da consciência e da liberdade dos indivíduos, entretanto, colabora para que persevere a ausência de liberdade.

Hegel apresenta a fragilidade de uma "preocupação com o fim ou os resultados, como também com as diversidades e apreciações dos mesmos, [que] é, pois, uma tarefa mais fácil do que talvez pareça" (2014, p. 25). Consiste em um julgamento antecipado que dispensa o trabalho de esforço 6 "com a Coisa mesma, passa sempre por cima. Em vez de nela demorar-se e esquecer a si mesmo [...] prefere ficar em si mesmo a estar na Coisa a abandonar-se a ela" (2014, p. 25). Esse é o caminho mais curto que o espírito utiliza para dominar a realidade e com isso tranquilizar-se e compelir uma desleal reconciliação. A trivialidade do julgar toma o espaço do trabalho, do esforço da percepção e do discernimento. "Nada mais fácil do que julgar o que tem conteúdo e solidez; apreendê-lo é mais difícil; e o que há de mais difícil é produzir sua exposição, que unifica a ambos" (HEGEL, 2014, p. 25).

Há que se ressaltar que essa condução é pelo caminho da dúvida, da problematização e do convite ao novo, à desconstituição das posições binárias e dicotômicas, a por em xeque toda e qualquer tentativa de homogeneidade que a mídia de massa só faz tentar incutir. Uma condução que precisa laborar na promoção de processos educacionais que permitam que se identifique e desconstrua as suposições em geral implícitas, que permita uma aproximação aberta à realidade de outrem, que labore pela quebra de perspectivas estáticas e essencialistas.

Engana-se aquele que pensa que a prática docente serve para ensinar delimitadamente alguma coisa, desprovido de aspecto político. Considerando que a aula é sempre um acontecimento, o que se ensina é a maneira como se envolve com aquele objeto, os caminhos que levam a compreendê-lo de uma ou de outra forma, que sempre são parciais, e isso não é nenhum demérito. Nesse sentido, é a alienação política do professor que acaba por incitar o formalismo didático, "que funciona como uma espécie de cinto de segurança. Daí o homem alienado, inseguro e frustrado, ficar mais na forma que no conteúdo; ver as coisas mais na superfície que em seu interior" (FREIRE, 2007, p. 25).

A alienação, acima descrita por Freire (2007), interfere diretamente na produção das práticas engendradas pelo professor, já que elas transitam no nível aparente. A não compreensão do seu aspecto político reduz as potencialidades das ações efetivamente transformadoras. Em contrapartida, ao assumir claramente sua condição política, ética e substancialmente democrática, o professor reconhece que tanto a prática educativa quanto a

${ }^{6} \mathrm{O}$ esforço, segundo o idealismo alemão, compõe o aspecto que realiza a mediação entre aquilo que é particular e o que é universal. 
formação humana estão sujeitas a "opções, rupturas, decisões, estar com e pôr-se contra, a favor de algum sonho e contra outro, a favor de alguém e contra alguém” (FREIRE, 1997, p. 39).

Comprometida com o seu caráter político, a prática pedagógica dialoga com a perspectiva de uma educação conscientizadora. Destarte, é imperativo perceber que não há conscientização se da prática pedagógica não resulta o movimento da consciência, se não se está, a todo momento, esperto, prestes a fazer a síntese, ainda que de modo provisório. Nesse sentido, torna-se clarificada a máxima freiriana de que "ninguém conscientiza ninguém. $\mathrm{O}$ educador e o povo se conscientizam através do movimento dialético entre a reflexão crítica sobre a ação anterior e a subseqüente ação no processo daquela luta" (FREIRE, 1981, p. 109110). Isso faz parte do movimento da consciência, da experiência dialógica, processo esse com o qual a didática necessita estar comprometida.

A didática, quando assume essa especificidade, rompe com os processos de alienação e mecanização que estão presentes na prática educativa e provoca a constituição de um ato efetivamente formativo, capaz de inserir os sujeitos em processos praxiológicos que os auxiliem a ler, de maneira mais acurada, o mundo, suas relações e contradições. Essa característica crítica da didática é essencial em se tratando da elaboração de uma proposta pedagógica que se comprometa com as classes populares e com as pelejas que se destinam a discutir gênero e raça, por exemplo. É aquela que se empenha na edificação de uma escola pública-popular "que supera os preconceitos de raça, de classe, de sexo e se radicaliza na defesa da substantividade democrática" e, desse modo, assume a luta "por uma crescente democratização nas relações que se travam na escola e das que se estabelecem entre a escola e o mundo fora dela" (FREIRE, 1997, p. 102).

Em Política e Educação, Freire disserta sobre esse aspecto da formação do homem, afirmando que "a prática educativa é tão interessada em possibilitar o ensino de conteúdos às pessoas quanto em sua conscientização". Logo, a educação popular, de matriz progressista e democrática que se contrapõe à educação bancária, reconhece "o esforço necessário de ter no educando um sujeito cognoscente, que, por isso mesmo, se assume como um sujeito em busca de, e não como a pura incidência da ação do educador" (1997, p. 28, grifo nosso).

Por fim, cabe ainda nesta discussão o registro sobre a necessária coerência entre o discurso e a prática na ação concreta do educador democrático. No cotidiano de seu trabalho na escola, submete sua opção à fundamental análise crítica da "possível e prazerosa experiência de falar aos educandos e com eles" (FREIRE, 1998, p. 87). Incitar a experiência da consciência por meio do diálogo, portanto, é princípio basilar de uma didática reflexiva 
que potencialize uma práxis voltada à compreensão dos fenômenos em sua essência, entre eles o educativo.

\section{Substantividade democrática na escola pública-popular}

Em Educação como prática da liberdade (1999), disse Freire que a educação da qual se necessita é aquela que, desnudada dos caracteres alienante e alienado, constitua uma potencialidade de libertação. Nesse aspecto reside a grande distinção "entre uma educação para a domesticação, para a alienação, e uma educação para a liberdade. Educação para o homem-objeto ou educação para o homem-sujeito" (1999, p. 44).

Uma educação para a liberdade nada tem a ver com o espontaneísmo e, nesse aspecto, a didática tem sido uma área bastante prejudicada por uma leitura extremamente descompromissada dos preceitos do pós-estruturalismo, o que acresce ainda mais a necessidade de combater o laissez-faire. Posicionamento equivocado esse que vem sendo adotado em nome de um suposto respeito à individualidade do aluno e que nada mais é que um espontaneísmo licencioso sob o pretexto de práticas não diretivas.

Entretanto, há que se considerar que "toda prática educativa transcende a si mesma, supondo um objetivo a ser atingido, não pode ser não-diretiva. Não existe prática educacional que não aponte para um objetivo. Isso prova que a natureza da prática educativa tem uma direção" (FREIRE, 1990, p. 86). A questão a ser posta é a intencionalidade e a forma como essa diretividade será abordada. A natureza diretiva da didática enquanto prática educativa precisa estar a serviço de um mesmo norte, conduzindo a um determinado objetivo, devendo ser vivida pelos educadores e educandos (FREIRE, 1990).

A essa afinidade intrínseca entre as relações políticas didático-pedagógicas e a liberdade da experiência da consciência é que Freire chamou de substantividade democrática. Nas palavras do autor, “o contrário positivo do espontaneísmo não é a manipulação e o contrário positivo dessa não é o espontaneísmo $\mathrm{O}$ contrário positivo de ambos é o que venho chamando de substantividade democrática" (FREIRE, 1990, p. 87). Categoria de análise essa que torna possível, no contexto da escola, ler o mundo, ler a realidade, ler a existência. "Assumir a diretividade da educação numa perspectiva democrática implica de um lado jamais reduzir os educandos a meras sobras, nem de outro anular a figura do educador, transformando-o numa ausência presente" (FREIRE, 1990, p. 87).

Essa substância democrática nada tem a ver com a ilusão de dar voz a alguém, jargão em voga que já parte do pressuposto pretensioso de que o educador é pertencente da mesma e 
autorizará os demais a fazer uso dela. A substantividade democrática é feita pelo extenso caminho da experiência, por fazer envolver o longo processo por que passa o conhecimento, por planejar com o método, cuja etimologia significa meta + hodos - caminho em direção a um fim - mas esse fim não tem sentido sem a experiência estética, sem a experiência formativa, sem a experiência da consciência.

Gaudêncio Frigotto (1989) lembra que o método freiriano de análise, no âmbito da perspectiva dialética materialista, não consiste em um instrumento asséptico, que enfoca a quantificação ou categorização de fenômenos sociais, que, segundo o autor, nas propostas lógicas e metafísicas são garantias da "cientificidade, da objetividade e da neutralidade" (p. 77). O caminho em direção a um fim na perspectiva freiriana está atrelado a uma concepção de realidade, de conjuntura, de estrutura e de vida, de modo não fragmentado. Para tanto, se faz necessário "revelar e expor a estruturação, o desenvolvimento e a transformação dos fenômenos sociais" (1989, p. 77). Compreender as estruturas sociais em sua razão de ser torna-se necessário para o entendimento da relação que essas estabelecem com a produção da vida e suas dimensões. $\mathrm{O}$ ato educativo, por seu turno, integra esse universo da prática produtiva, simbólica e social, sendo um produto dessas mediações da existência humana e, ao mesmo tempo, um elemento que as medeia (SEVERINO, 1994).

A práxis pedagógica que se compromete com a substantividade democrática, ao promover a mediação dialética entre as relações provenientes do mundo do trabalho, da cultura e da política, quando desenvolvida no contexto da escola, tem como uma de suas tarefas indispensáveis “inserir os grupos populares no movimento de superação do saber de senso comum pelo conhecimento mais crítico, mais além do 'penso que é', em torno do mundo e de si no mundo e com ele" (FREIRE, 1997, p. 29).

A didática, partindo do pressuposto acima, assume empreitada constitutiva desse processo, pois possibilita o desenvolvimento de uma práxis intencional, não espontânea, que potencializa a elevação do saber de experiência feita a uma condição mais crítica e capaz de perceber as relações do sujeito com o outro e com o mundo. É um processo que, de base popular, realiza-se em um tempo-espaço de possibilidades e que permite aos sujeitos uma consciência mais crítica dos fenômenos. É um movimento que também não prescinde do sonho (FREIRE, 1997). O professor, nesse cenário, entrega-se "a uma prática educativa e a uma reflexão pedagógica fundadas ambas no sonho por um mundo menos malvado, menos feio, menos autoritário, mais democrático, mais humano" (FREIRE, 1997, p.30). O menos, destacado por Freire, não representa um reformismo diante do sistema social-econômico capitalista e seus processos de dominação, alienação e exploração. $\mathrm{O}$ advérbio caracteriza a 
ação inserida no espaço das possibilidades objetivas, históricas e sociais que se manifestam na realidade. É o inédito-viável e suas potencialidades de ações transformadoras em diálogo com o horizonte da mudança social radical.

$\mathrm{Na}$ articulação entre a ação educativa e o projeto de sociedade, "a educação popular cuja posta em prática, em termos amplos, profundos e radicais, numa sociedade de classe, se constitui como um nadar contra a correnteza é exatamente a que, substantivamente democrática", em tempo algum "separa do ensino dos conteúdos o desvelamento da realidade" (FREIRE, 1997, p. 101). O trabalho com o ensino dos conteúdos, por meio de uma didática crítica e com clareza de sua intencionalidade formativa, provoca o estranhamento do sujeito ante o mundo e sua constituição, permite a ele compreender seus aspectos ideológicos e fazer o uso desses conteúdos como ferramentas para melhor operar nas situações concretas de seu cotidiano. Tornar-se sujeito e não mero expectador nas relações no/com o mundo e no espaço pedagógico requer o exercício de envolver-se com experiências que permitam pensar "o tempo, $[\ldots]$ pensar a técnica, $[. .$.$] pensar o conhecimento enquanto se conhece, [\ldots]$ pensar o quê das coisas, o para quê, o como, o em favor de quê, de quem, o contra quê, o contra quem" as quais "são exigências fundamentais de uma educação democrática" (FREIRE, 2014, p. 18), imprescindíveis na hodiernidade e na construção de um outro mundo, de relações mais humanizadas e de uma educação radicalmente popular e promotora de outras percepções.

A práxis educativa, inserida em um projeto popular e democrático de escola, responsabiliza-se politicamente com a diretividade do ensino e da aprendizagem, estando continuamente aberta à realidade contextual daqueles com os quais dialoga para que, desse modo, possa compreendê-los substancialmente, bem como conhecer as relações que esses sujeitos estabelecem com o contexto a que pertencem (FREIRE, 1998). Na articulação com as práxis educativas, voltadas ao campo da educação popular, a substantividade democrática ainda assume seu caráter político na concretização do sonho da produção de um novo modo de experienciar a existência. Freire assevera categoricamente que é viável uma "vida sem sonho, mas não existência humana e História sem sonho". Assim, a educação popular possibilita que "a compreensão geral do ser humano em torno de si como ser social seja menos monolítica e mais pluralista, seja menos unidirecionada e mais aberta à discussão democrática de pressuposições básicas da existência" (1997, p. 30), precavendo-se do engodo de deter-se na mera socialização do já conhecido e do já experienciado por aquelas classes.

Uma existência estribada na luta pelo sonho da humanização, que reconheça que a história é construída pelos sujeitos em suas andarilhagens no/com o mundo e com os outros, assume a sua politicidade contra todos os contextos de opressão, assegura um processo 
educativo popular substantivamente democrático e capaz de promover rupturas com a lógica alienante, potencializa o ser mais nas mais variadas experiências formadoras, sem precisar negar a sua diretividade.

\section{Considerações finais}

Introduzido pela conhecida crítica ao formalismo didático, mas cotejando-a a preceitos filosóficos que se debruçaram sobre a experiência da consciência, o presente estudo buscou operar com a concepção de substantividade democrática, proposto pela pedagogia freiriana, e colocá-la em diálogo com o processo formativo em uma perspectiva popular. Considera-se, com isso, que os movimentos vinculados ao ensino e à aprendizagem ganham concretude e se reestruturam em uma perspectiva crítica, diretiva e popular, redimensionando a experiência da consciência e assumindo a intencionalidade desse processo. Reconhece-se que existe um caminho a ser trilhado e que esse favorece a percepção reflexiva dos envolvidos sobre as suas experiências estéticas e formativas, experiências que produzem consciência.

Fundada ainda no diálogo, a substantividade democrática provoca os educandos a dizerem a sua palavra, que somente torna-se possível mediante o compromisso de respeito ao saber do outro e à sua voz. Dialogar também pressupõe responsabilidade com a emergência de análises cada vez mais críticas sobre as experiências vivenciadas no/com o mundo, responsabilidade com a problematização daquilo que constitui o conteúdo do diálogo.

É sempre uma tarefa complexa e conflitante abordar a teoria freiriana, haja vista tanto a simplificação que sofreu ao longo do tempo quanto o esfacelamento de relevantes aspectos políticos dos seus escritos. No entanto, é deveras frutífera a experiência de, rigorosamente, perguntar e perguntar novamente aos seus conceitos o que estão nos dizendo, considerados seu tempo e seu espaço. Brayner (2015) já denunciou a institucionalização dos ditos de Freire, do seu pensamento e o que tudo isso acarretou para a educação popular.

A constituição de um fluxo de seguidores - por mais doído que o termo seja -, divulgadores, admiradores e comentadores concentrados em universidades e que, sob a égide da salvaguarda da sua tradição intelectual e do discurso revolucionário desse educador, acabou por convertê-lo em um autor, tratado assim de modo grifado para enfatizar o sentido de ponto irradiador de referências, menções e comentários. O que não somente enfraqueceu uma concepção pedagógica de educação popular, mas, sobretudo, preceitos estéticos, culturais e políticos que fundamentam para além do fazer da sala de aula, mas modos de se relacionar com o mundo e com o outro. Nesse sentido, são válidas as reflexões sobre concepções 
fundamentais que visem a contrapor a construção do que Brayer (2015) chamou de instituição Paulo Freire, e isso se realiza por meio do esforço tenso tanto de reflexão sobre seus conceitos quanto de compreensão de suas mais basilares críticas.

\section{REFERÊNCIAS}

ADORNO, Theodor. Teoria da Semicultura. Trad. Newton Ramos-de-Oliveira. In: Educação e sociedade. Campinas: Papirus, 1996. Ano XVII, n. 56, p. 388-411.

BATALLOSO NAVAS, Juan Miguel. Didáctica deconstructiva y complejidad: Algunos principios. In. Moraes, M. C. \& Batalloso N.. J. M. (Orgs.). Complexidade e transdisciplinaridade em educação: teoria e prática docente. Rio de Janeiro: Editora WAK, 2010.

BORGES, Jorge Luís. O Aleph. Trad. Davi Arrigueei Jr. São Paulo: Companhia das Letras, 2008.

BRAYNER, Flavio Henrique Albert. Paulofreireanismo: instituindo uma teologia laica? Trabalho Encomendado GT06 - Educação Popular, 37ª Reunião Nacional da ANPED, 4 a 8 de outubro de 2015, Florianópolis, UFSC.

CANDAU, Vera Maria (Org.). Didática crítica intercultural. Petrópolis, RJ: Vozes, 2012.

CANDAU, Vera Maria (Org). Rumo uma nova didática. 23. ed. Petrópolis, RJ: Vozes, 2013.

FREIRE, Paulo. Ação cultural para a liberdade. 5. ed. Rio de Janeiro: Paz e Terra, 1981.

FREIRE, Paulo; MACEDO, Donaldo. Alfabetização: leitura do mundo, leitura da palavra. São Paulo/Rio de Janeiro: Paz e Terra, 1990.

FREIRE, Paulo. Educação como prática da liberdade. 23. ed. Rio de Janeiro: Paz e Terra, 1999.

FREIRE, Paulo. Educação e Mudança. 30. ed. Trad. Moacir Gadotti e Lilian Lopes Martin. Rio de Janeiro: Paz e Terra, 2007.

FREIRE, Paulo. Pedagogia da indignação: cartas pedagógicas e outros escritos. São Paulo: Editora UNESP, 2014.

FREIRE, Paulo. Pedagogia do Oprimido. Rio de Janeiro: Paz e Terra. 2005.

FREIRE, Paulo. Política e educação: ensaios. 3. ed. São Paulo: Cortez Editora: 1997.

FREIRE, Paulo. Professora sim, tia não: cartas a quem ousa ensinar. 9. ed. São Paulo: Editora Olho d'Água, 1998. 
FREITAS, Luiz Carlos de. Crítica da organização do trabalho pedagógico e da didática. 1994. 305p. Tese de Livre Docência apresentada à Faculdade de Educação da UNICAMP Universidade Estadual de Campinas, Campinas.

FRIGOTTO, Gaudêncio. O enfoque da dialética materialista histórica na pesquisa educacional. In: FAZENDA, Ivani (Org.). Metodologia da pesquisa educacional. São Paulo: Editora Cortez, 1989. p. 70-90.

GADOTTI, Moacir. Convite à leitura de Paulo Freire. São Paulo: Editora Scipione Ltda, 1989.

HEGEL, Georg Wilhelm Friedrich. Fenomenologia do Espírito. Petrópolis: Vozes, 2014.

LIBÂNEO, José Carlos. Escola pública brasileira, um sonho frustrado: falharam as escolas ou as políticas educacionais? In: LIBÂNEO, José Carlos; SUANNO, Marilza Vanessa Rosa (Orgs.). Didática e escola em uma sociedade complexa. Goiânia, GO: CEPED/UFG, 2012.

PASQUIM. Paulo Freire, no exílio, ficou mais brasileiro ainda. Rio de Janeiro, n. 462, dezembro de 1978. p. 07-11.

MCLAREN, Peter. A pedagogia da possibilidade de Paulo Freire. Educação, Sociedade \& Culturas, Porto/Portugal, n. 10, p. 57-82, 1998.

MCLAREN, Peter. Utopias provisórias: as pedagogias críticas num cenário pós-colonial. Rio de Janeiro: Vozes, 1999.

SEVERINO, Antônio Joaquim. Filosofia da Educação: construindo a cidadania. São Paulo, FTD, 1994.

TORRES, Carlos Alberto. De Pedagogia do Oprimido à Luta Continua: a Pedagogia Política de Freire. In: MCLAREN, Peter; LEONARD, Peter; GADOTTI, Moacir (Orgs.). Freire: Poder, desejo e memórias de libertação. Porto Alegre: ArtMed, 1998. p. 77-102.

\section{Como referenciar este artigo}

GHIGGI, Gomercindo.; CHAVES, Priscila Monteiro.; PEREIRA, Dirlei de Azambuja. Do formalismo didático à experiência da consciência: Paulo freire e a substantividade democrática na escola pública-popular. Revista Ibero-Americana de Estudos em Educação, Araraquara, v. 14, n. 1, p. 46-62, jan./mar., 2019. E-ISSN: 1982-5587. DOI: 10.21723/riaee.v14i1.11144

Submissão: 01/02/2018

Revisões requeridas: 03/03/2018

Aprovação final: 24/08/2018 